\title{
THE 150TH ANNIVERSARY OF THE MOORFIELDS MEDICAL SCHOOL
}

It seems a good opportunity, on the 150th anniversary of the founding of the Medical School of Moorfields Eye Hospital, to take note of the earliest ophthalmic hospital to be founded in the world, which still survives and which has provided the inspiration for the foundation of eye hospitals as far apart as the United States of America in the West and India in the East. The two following papers were delivered at Moorfields to the Osler (Historical) Club and may be of interest to our readers.

THE EDITOR

\section{THE HISTORY OF THE MOORFIELDS MEDICAL SCHOOL}

\author{
BY

\section{CHARLES COOK}

THERE can be little doubt that the concept of an institution entirely devoted to the treatment of and instruction in ocular diseases in the early years of the 19th century can to a great extent be correlated with the enormous increase in ocular diseases which followed the Napoleonic War. A fulminating infection of the eye, the so-called "Egyptian ophthalmia" swept through the English troops defending Egypt, and after their evacuation and disbandment in 1803 , this ocular condition, which was almost certainly trachoma complicated by other infections, spread rapidly throughout Great Britain. The virulent nature of the disease is well demonstrated by its effects on the second battalion of the 52nd Light Infantry in which, out of 636 infected soldiers, fifty lost both eyes and forty suffered the loss of one. Unfortunately the disease did not remain confined to the army, but was disseminated widely among the civilian population.

At this period, in spite of the ever-increasing incidence of ocular disease, the study of ophthalmology was almost entirely neglected in the teaching hospitals, its practice being essentially left to itinerant quacks, or so-called oculists. This taint of quackery naturally had the effect of deterring respectable surgeons from either practising or teaching the subject. It is interesting to note, however, that several of the quack fraternity, although looked upon as charlatans by the medical profession, had most successful careers. Thus one William Read, who started life as a tailor, settled in London in 1694 and advertised in the Tatler that he was adept in the technique of couching cataracts, taking off all sorts of wens, and curing wry-necks and hair-lips without blemish. In 1705 he was knighted and was at the same time 
appointed Oculist-in-Ordinary to Queen Anne. One sample only of his methods of treatment needs be quoted: "A louse put into the eye when it is dull and obscure and wanteth humours and spirits, tickleth and pricketh so that it maketh the eye moist and rheumatic and quickeneth the spirits". Then there was Roger Grant, a cobbler, who subsequently became a Baptist minister. The best known and most notorious of this fraternity was John Taylor, better known as Chevalier Taylor, who stands pre-eminent for unblushing effrontery whilst indulging in all the methods of the charlatan, and yet was appointed by King George II as his oculist.

Thus, in 1803, when John Saunders returned to London to practise surgery, there was an immense increase in the amount of eye disease and practically no provision for its treatment. His interest had already been attracted to ophthalmology during his apprenticeship, and after starting general practice he decided to devote himself entirely to ophthalmology, a decision which must have required considerable courage in one who wished to remain of good repute with other members of his profession. The suggestion that Saunders should start a special institution for the treatment of the eye and ear is said to have originated with his patron, Astley Cooper. The greatest London surgeon of his day, he had taken considerable interest in his protégé, who had served as his demonstrator of anatomy at St. Thomas's Hospital.

After seeking the advice and obtaining the approval of the physicians and surgeons of St. Thomas's and Guy's Hospitals, on October 1st, 1804, he published a proposal for opening a dispensary for the poor suffering from diseases of the eye and ear. A committee was then formed under the chairmanship of Mr. Benjamin Travers, a wealthy city merchant, and at its first meeting, held at the City Coffee House on January 4, 1805, it was unanimously agreed that "a dispensary be instituted under the name of the London Dispensary and that Dr. Farre be appointed consulting physician for cases requiring medical aid".

Subscriptions from many city merchants enabled the lease of 40 Charterhouse Street to be purchased for 18 years for a sum of $£ 300$ and an annual rental of $£ 65$, and on March 25, 1805, the "London Dispensary for Curing Diseases of the Eyes and Ears" was opened for the reception of patients. (Fig. 1, opposite).

One Sarah Clerk was appointed nurse and housekeeper and her husband was engaged to dispense drugs, their combined salary being $£ 50$ per year together with coal and candles. The institution undoubtedly satisfied a great need, for during the first year 600 patients were admitted of whom 500 were said to be cured; by the fourth year the numbers had risen to 2,357 patients of whom 1,970 were "cured". The term "cured" has unfortunately to be construed in the widest sense, for amongst those patients so named were included cases of complete corneal opacity in which it would 


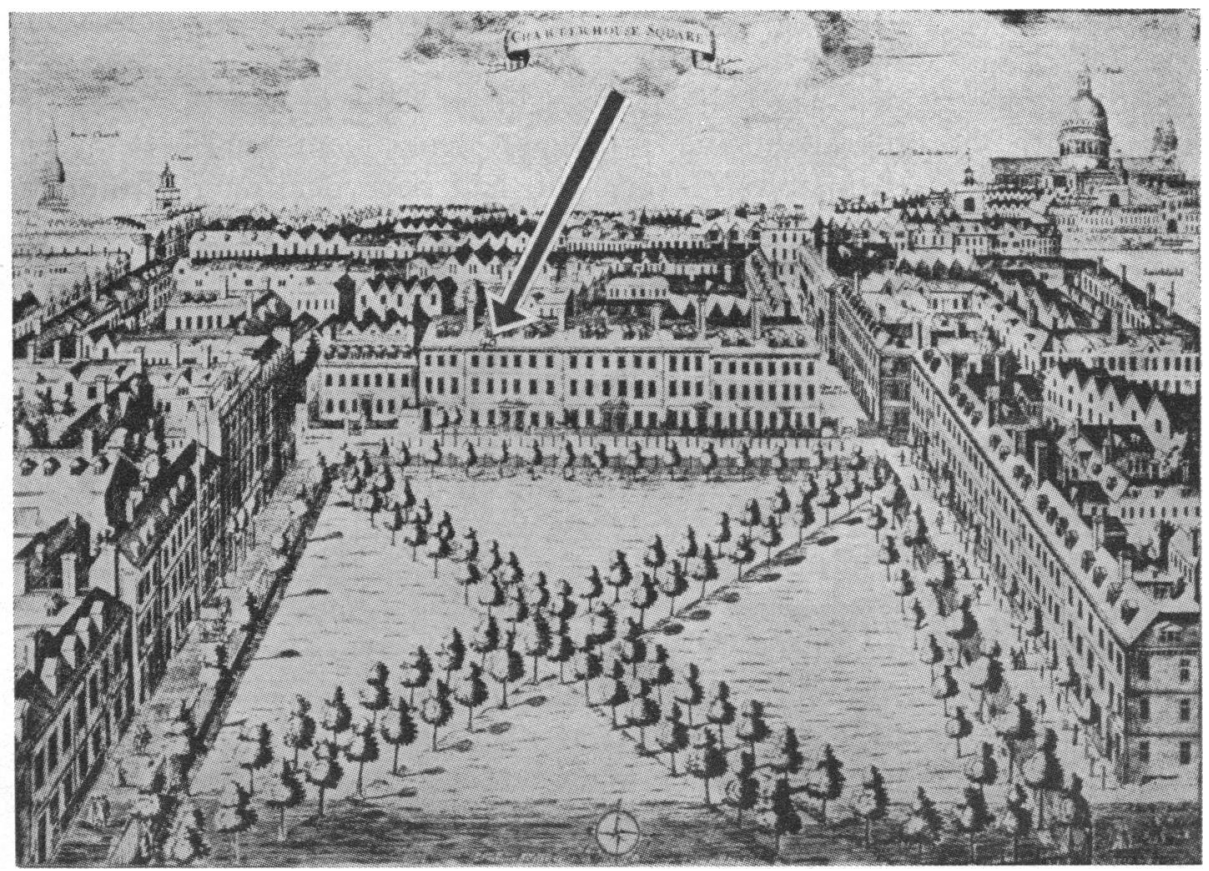

FIG. 1.-The first hospital.

The London Dispensary for Curing Diseases of the Eyes and Ears (arrowed), opened in 1805.

appear to be obvious that although the treatment might have been successful the patient remained blind.

In December, 1807, at Saunders's request, the governors resolved that diseases of the eye should be the sole object of the charity, and that the name of the institution should be changed to "The London Infirmary for curing Diseases of the Eye". The reason for this change of name is interesting: "apart from the removal of inspissated wax from the external ear, there was not any useful treatment for deafness".

By 1809 Saunders had two pupils working with him at the Dispensary, both of whom subsequently became ophthalmic surgeons. William (afterwards Sir William) Adams founded the "West of England Eye Infirmary" at Exeter and became oculist to the Prince Regent. John Stevenson founded the "Royal Infirmary for Cataract and Other Diseases of the Eye" in London in 1830 under the patronage of King William IV to whom he was appointed oculist; this hospital survived for only 14 years.

It should perhaps be recorded that Saunders was not the very first man to specialize in eye diseases, nor indeed was the hospital he founded in 1805 the first eye hospital to be opened in London, for a Dr. Wathan and a Dr. Ware actually started a hospital in Cork Street in 1804 under the patronage of George III, which was known as "The Royal Infirmary for Diseases of the Eye". This hospital survived only until 1872. It subsequently handed 
over its assets, amounting to $£ 200$, to the Royal London Ophthalmic Hospital.

After Saunders's death in 1810, Astley Cooper temporarily took over the care of both the out-patient and in-patient departments until Benjamin Travers, son of the Benjamin Travers who had been chairman of the first Committee set up in 1805 (see above), was elected to fill the vacancy. Travers had been trained as a general surgeon, and indeed was eventually so appointed to St. Thomas's Hospital. He combined the practice of ophthalmology with general surgery and did much to carry on the work of Saunders in raising the specialty from the condition of quackery in which it had begun. His connexion with St. Thomas's enabled him to bring his students to the Eye Infirmary for special instruction, and in 1810, at his instigation, the practice of the Infirmary was opened to medical students. In the annual address of the committee of the London Infirmary for that year it is noted that "permission has been granted to the medical officers to deliver lectures. The attention of the Committee has also been occupied with the means of extending the immediate circle of its operation. With this view they have permitted the practice of its Medical Directors to be attended by students by which act they provide that a knowledge of the diseases of the eye shall be more generally diffused among the members of the medical profession".

So was initiated the school of ophthalmology. Among the earliest students were two young Americans, Dr. Edward Delafield and Dr. J. Kearney Rodgers, who, on their return to New York, established the New York Eye and Ear Infirmary in 1820 on lines similar to the English institution. This hospital survives as one of the leading ophthalmic hospitals in the U.S.A., and, unlike its parent institution, has retained the old title of Infirmary. It is interesting that Dr. Delafield was elected the first president of the American Ophthalmological Society on its foundation in 1864. A few years later Dr. Edward Renold came from Boston, Mass., to study at the Eye Infirmary and was responsible on his return to the United States for the foundation of the Massachusetts Charitable Eye and Ear Infirmary.

In 1819 the Directors of the East India Company consulted Travers (who was surgeon to their Company) as to the best method of coping with the ocular diseases which were rife in the populous districts which they controlled, and at his suggestion one of the surgeons of the Company who had studied under him at the Infirmary was sent to Madras where he founded the Madras Eye Infirmary; such was its success that 5 years later other Eye Infirmaries were founded at Bombay and Calcutta by former students of the English institution.

During the first 7 years that the London Eye Infirmary was open to medical students, 412 pupils from many countries (including the United Kingdom, India, America, and Germany) had received instruction, and 10 years later the number had increased to over 1,000 students from every 
part of the world who, according to the Annual Report of the Hospital, "had diffused the hospital's benefits over various remote parts of the globe so that it is perhaps as well known on the banks of the Ganges as on the banks of the Thames".

The chief financial support of the Infirmary at this time was derived from subscriptions and donations received at the anniversary dinners, at which, up to 1812, were exhibited patients of special interest and those showing post-operative results best calculated to stimulate generous contributions from the diners. Another technique was to obtain the services of some eminent divine to preach a sermon on behalf of the Infirmary on the Sunday before the dinner, and such was the response that, in spite of the then enormous cost of the Peninsular War, the funds rose steadily and in 1819 were sufficiently great to enable a Building Committee to be appointed to find a suitable site and to draw up plans for a larger institution better equipped to cope with the ever-increasing clinical and teaching demands.

On May 2, 1821, the foundation stone of a new Infirmary was laid in Moorfields (a piece of moorland to the north of the old City Wall, access to which was gained through the Moorgate). Early in the 17th century this had been drained, laid out in walks, and planted with trees, and was a wellknown place of recreation. On the laying of the foundation stone of the new building its name was changed for the second time to the "London Ophthalmic Infirmary", but it rapidly became more generally known as "Moorfields Eye Hospital" (Fig. 2). It was not the first Moorfields Hospital, however, for the Bethlehem Royal Hospital for Lunatics had been built in Moorfields in 1675.

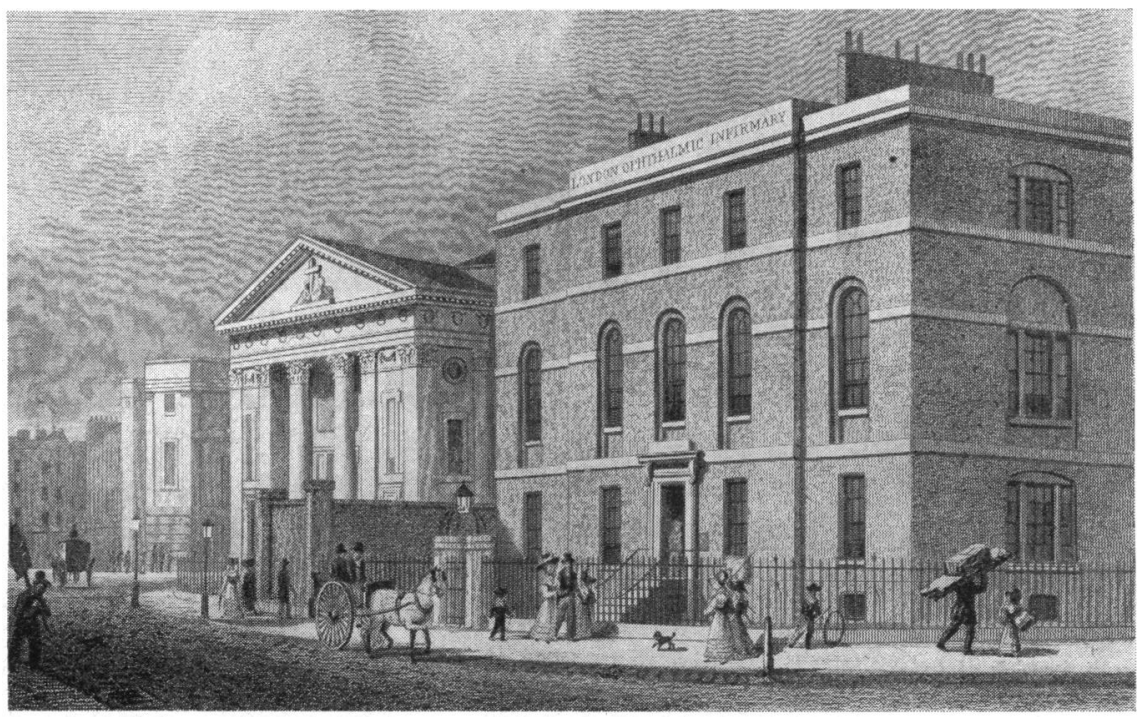

Fig. 2.-The second hospital.

The London Ophthalmic Infirmary, 1822. 
On November 12,1822 , an introductory lecture announcing the arrangement of a course of instruction was given by Dr. Farre, who was thus the first to institute a planned scheme of instruction for the students; he was also instrumental in stressing in this scheme the paramount importance of relating clinical.signs and symptoms with pathological findings.

The Duke of York, the Infirmary's first Patron, died in 1827, and the Duchess of Kent and her daughter Princess Victoria, the heiress presumptive to the throne, gave their consent for their names to be placed as Patronesses to Moorfields. The Board of Governors thereupon decided that the name of the Infirmary should be changed to the "Royal London Ophthalmic Hospital, Moorfields", and after Queen Victoria's accession to the throne in 1837 her patronage continued throughout her long reign.

As the fame of the Hospital extended, there was a progressive increase in the number of out-patients and the annual number of new patients was doubled in the course of 10 years. In 1841, there were 5,043, and in 1851, 11,384 patients. The out-patient department was therefore enlarged, and another assistant surgeon, a Mr. Wordsworth, a descendant of a collateral branch of the poet's family, was eventually appointed to the staff. Although not relevant to the present discussion, a story related of him by Treacher Collins may be worth the telling. Wordsworth resided and practised in Finsbury Square, the fashionable medical residential quarter in London at that time, but his private patients were few and far between. He therefore employed a page-boy to fetch him from the hospital if any patient should happen to call at his rooms whilst he was engaged on hospital duties. One day the boy came hurriedly to the hospital, to announce the arrival of a patient. "Will he wait until I get round?", Wordsworth asked the boy. "I am quite certain he will", replied the boy, "for I have locked him in". Wordsworth then told his house surgeon that he had been called away to see a private patient, and away he went with the boy. To everyone's great surprise he returned after only a few minutes, and noting the look.of inquiry on their faces, ruefully explained that it had been only the tax-collector.

In 1854, in order to help non-medical missionaries, a departure from the usual custom was made when the Committee of Management obtained the consent of the medical staff to admit non-medical personnel to the practice of the hospital, provided that a missionary society certified that they were about to proceed on missionary duties abroad. A letter was circulated to the missionary societies and a large number of both men and women availed themselves of these facilities.

As the work increased, the medical board of the hospital proposed in 1856 that some of the younger doctors should be elected to serve as assistants to the surgeons. They had in mind that thus they could not only assist in the clinical work of the out-patient department, but also, given this opportunity, might practise and teach their skill in all parts of the world on 
relinquishing their appointments. In this way for the first time an organized scheme of training was introduced which was designed to send out from Moorfields fully-trained ophthalmologists to fill consultant vacancies not only throughout England but over a large part of the globe.

In 1859 the clinical teaching was supplemented by a 3 months' course of lectures in ophthalmic surgery given by Sir George Critchett and Sir William Bowman, attendance at which enabled students to comply with the rules of the Royal College of Surgeons of England for obtaining a certificate of proficiency; in 1864, evening ophthalmoscopic demonstrations were started for the students and were conducted in turn by different members of the staff.

When the Eye Infirmary was first built in Moorfields in 1821 the district was extremely quiet, but by 1899 when the Eye Hospital was transferred to City Road, it had become one of the busiest and noisiest quarters of the city, mainly because of the opening of the Broad Street and Liverpool Street railway stations almost opposite the hospital itself. Moreover, the greater facilities for travel offered by the railways led to a marked increase in the number of out-patients. A new wing providing an additional 36 beds was therefore added to the south side of the hospital in July, 1870, and a further storey, built onto the main building, was opened in 1875, the total accommodation being thus increased to 45 beds for male patients and 51 for women and children. The design of these additions was apparently not everything that could be desired, however, and Treacher Collins noted amongst other defects a curious device of placing the fireplaces immediately beneath the windows. This necessitated an elbow-shaped bend in the flue where soot collected and regularly caught fire, causing consternation and excitement amongst the patients and resident staff. The addition of the wing, however, made more laboratory space available, and courses of instruction in the practical pathology of the eye were thereupon commenced by the curator.

In 1873, a Canadian, Frank Buller, was appointed house-surgeon, and, subsequently returning to Montreal, became the pioneer of ophthalmic surgery in Canada. In so doing Buller forestalled another young Canadian, named William (afterwards Sir William) Osler, who had come to Moorfields to study eye diseases with the same end in view, but learning there of Buller's intentions abandoned the practice of ophthalmology for that of general medicine.

Although the original Moorfields Hospital was enlarged and altered to meet increasing demands, it eventually became impossible to cope adequately with the growing number of patients, students, and trained ophthalmologists from all parts of the world whom its spreading reputation drew to the hospital, and it.became obvious that nothing but a new building would meet its requirements. After several sites had been explored, a lease was eventually obtained for 999 years from March, 1894, of what was termed the City 
Road and Peerless Street site, at a rent of $£ 1,210$ per annum, and on May 28, 1897, the Prince of Wales (afterwards King Edward VII) on behalf of Queen Victoria laid the foundation stone of the new hospital. The new building was officially opened as the Royal London Ophthalmic Hospital by the Duke and Duchess of York (afterwards King George V and Queen Mary) on June 28, 1899 (see left-hand side of Fig. 3, opposite). The old hospital was sold for $£ 78,500$ while the new hospital cost approximately $£ 85,000$. It is interesting to note that the cost of maintenance of the old building was about $£ 8,000$ per year, whilst that of the new hospital was estimated at approximately $£ 11,000$ per annum in 1899 , a figure which may be compared with the present annual expenditure of $£ 850,000$.

In the new hospital a large room was set apart as a lecture theatre and, as the teaching became more systematized and the number of students increased, a Dean was appointed to supervise the classes and to advise the students about their studies; to this post Mr. Holmes Spicer. was officially elected in 1899, although successive surgeons had almost certainly carried out the same office previously, at least since the appointment of William Bowman. The teaching at Moorfields up to 1920, when the Royal College of Physicians of London and the Royal College of Surgeons of England established a diploma of ophthalmology, was almost entirely clinical and pathological. In order to obtain the diploma of ophthalmology, however, it became necessary for students to pass an examination in optics and in the anatomy and physiology of the eye and its adnexa. To meet the requirements of candidates for this examination, therefore, special courses of instruction in these subjects were instituted at Moorfields which thus became a complete school of ophthalmology.

The most recent stage in the evolution of the Medical School was reached after the Second World War, when the British Postgraduate Medical Federation was formed within the University of London, and the Medical School of Moorfields was invited to join the Federation as an Institute of Ophthalmology. To coordinate all that was best in London and to circumvent the immense difficulties in the immediate post-war period of finding or erecting new buildings, the Royal London Ophthalmic Hospital combined with the Central London Ophthalmic Hospital (founded in 1843) and later with the Royal Westminster Ophthalmic Hospital (founded in 1816), a combination confirmed by Act of Parliament on January 1, 1947. Such a combination gave scope for wide planning within the three units, so that the old Central London Ophthalmic Hospital in Bloomsbury became converted into a research and teaching institute, and the other two hospitals in the City Road and in High Holborn were united under the historical name of Moorfields Eye Hospital, to act as associated clinical units. The first building was reconstructed to house laboratories, a library, a museum, and clinical research units, and in 1948 the Institute of Ophthalmology was formally 


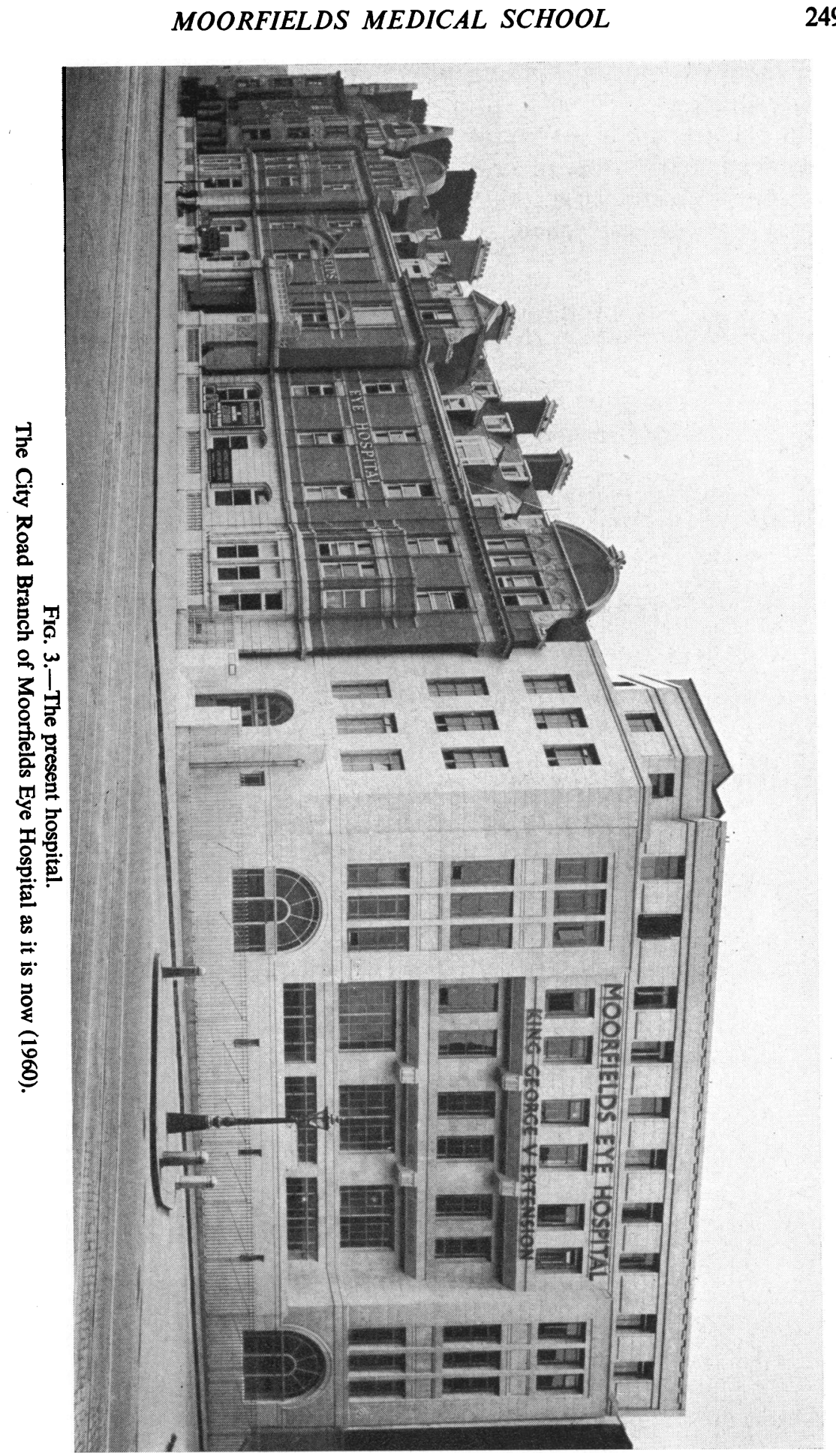


incorporated into the University of London as its postgraduate school of ophthalmology. The official opening ceremony was held on November 4, 1948, before an audience of delegates of British Universities; British, American, and European ophthalmology were represented respectively by Sir John Parsons, Prof. Alan Woods, and Prof. H. J. M. Weve. Here to-day the Medical School of Moorfields maintains the traditions of 150 years.

All who have read 'The History and Traditions of the Moorfields Eye Hospital' will know how much this article owes to the late Mr. Treacher Collins, and I most gratefully acknowledge this debt. 